\title{
Erratum to: Role of inlet reactant mixedness on the thermodynamic performance of a rotating detonation engine
}

\author{
C. A. Nordeen ${ }^{1}$ - D. Schwer ${ }^{2}$ - F. Schauer ${ }^{3} \cdot$ J. Hoke ${ }^{4}$ - T. Barber ${ }^{1}$ - B. M. Cetegen ${ }^{1}$
}

Published online: 19 July 2016

(C) Springer-Verlag Berlin Heidelberg 2016

\section{Erratum to: Shock Waves}

\section{DOI 10.1007/s00193-015-0570-7}

Unfortunately, in the original online publication of the article, the quantity $I_{\mathrm{sp}}$ was incorrectly typeset as $I s p$ in the following places: in the text of Sect. 3 (4 cases); in Eq. (10); in Table 1 (4th column). In Eq. (14), the subscript "s, rej." has a period which should be removed.

The original publication of the article has been updated to reflect these changes. 